\title{
Long-term Field Corrosion Monitoring in Supporting Structures of China Xiamen Xiangan Subsea Tunnel
}

\author{
Chao-Yang Gong ${ }^{1,2} \cdot$ Xiao-Yong $\mathrm{He}^{1} \cdot$ Yong-Wei $\mathrm{Li}^{1} \cdot \mathrm{Si}$-Zhe $\mathrm{He}^{1} \cdot$ Xuan Cheng $^{1,2} \cdot$ Liu-Ying Huang $^{1,2}$. \\ Ying Zhang ${ }^{1,2} \cdot$ Jiu-Bin Chen ${ }^{3} \cdot$ Shao-Hui $\mathrm{Xu}^{3} \cdot$ Jian-Bin Zhang ${ }^{3} \cdot$ Chao Zeng $^{3}$
}

Received: 20 August 2016/Revised: 3 January 2017/Published online: 21 February 2017

(c) The Chinese Society for Metals and Springer-Verlag Berlin Heidelberg 2017

\begin{abstract}
Xiamen Xiangan Subsea Tunnel is the first undersea tunnel constructed in China. It has become the major undersea pathway connecting Xiamen Island and Xiangan District since its operation in 2010. The total length is $6.05 \mathrm{~km}$ with the undersea length of $4.2 \mathrm{~km}$. In an effort to onsite-monitor reinforcement corrosion in concrete structures, the commercially available CorroWatch multiprobe sensors and ERE-20 reference electrodes were pre-embedded in the selected locations and positions of supporting structures during the tunnel constructions. The real-time data have been collected annually by onsite measurements for 6 years. In this paper, the feasibility of the onsite corrosion monitoring system and suitability of the measured parameters including corrosion current, potential and temperature are discussed based on the preliminary results. The measured typical cyclic-type variations in corrosion current and temperature with monitoring time might be related to the seasonal changes during the annual routine measurements. The widely scattered corrosion potentials that are fluctuated complicatedly reflected localized differences in the vicinity of rebar and concrete. These findings, along with the progressively ongoing research, will provide valuable information in structural durability for service life prediction of reinforced concrete structures exposed to marine environments.
\end{abstract}

KEY WORDS: Corrosion monitor; Corrosion current; Corrosion behavior; Sensors

\section{Introduction}

Reinforcement corrosion in concrete structures has been widely recognized and extensively investigated as it detrimentally influences the durability and safety of engineering structures. The mechanisms and effects of

Available online at http://link.springer.com/journal/40195

Xuan Cheng

xcheng@xmu.edu.cn

1 Department of Materials Science and Engineering, College of Materials, Xiamen University, Xiamen 361005, China

2 Fujian Key Laboratory of Advanced Materials (Xiamen University), Xiamen 361005, China

3 Xiamen Road and Bridge Construction Group Co., Ltd, Xiamen 361000, China reinforcement corrosion, the monitoring techniques and methodologies used in reinforcement corrosion, and the methods employed for prediction of remaining service time have been previously reviewed $[1,2]$. The major factors that can affect the reinforcement corrosion and concrete deterioration include external environments, such as chloride concentration, moisture, oxygen, humidity, temperature, bacterial attack, stray currents, and concrete quality, such as carbonation, acid gas penetration, cement content, impurities, surface cracks. It is, therefore, practically desirable to onsite-monitor the reinforcement corrosion in concrete structures for durability assessment and safety maintenance of engineering structures exposed to harsh environments.

Many efforts have been made directly toward developing sensitive and effective corrosion sensors. Depending on situations, some surface corrosion sensors are usually selected for the existing structures, while embedded 
corrosion sensors are more suitable for the structures under construction. Presently, most nondestructive and embedded corrosion sensors are mainly based on the macrocell principle. Since rebar corrosion is an electrochemical process, potential differences will be created by changes of dissociative iron ions at an anode zone and reduction of oxides at a cathode zone in different positions of rebar, resulting in measurable galvanic corrosion currents. The macrocell corrosion refers to the corrosion process taking place in large anodic and cathodic zones. By using black steel as an anode and noble material as a cathode, a macrocell can be formed. The electrochemical potentials of the anode and cathode in healthy concrete structures are nearly identical, and therefore, the galvanic current passing through the anode and cathode is approximately zero. When the black steel corrodes in the concrete due to the attack of corrosive species (e.g., chloride, carbonate), the potential at the anode drops, and the potential at the cathode normally remains unchanged. Therefore, the current flowing between the anode and cathode varies significantly. Accordingly, the time-to-corrosion may be estimated from the signals of different anodes. The limited applications in bridges, subways and tunnels with embedded corrosion sensors, such as anode-ladders [3, 4], CorroWatch multiprobe, ERE-20 reference electrode [5], ECi-2 [6] and multifunctional sensor [7] have been demonstrated to monitor corrosion risk onsite. The key monitoring parameters include corrosion current, corrosion potential or open-circuit potential, $\mathrm{pH}$, concentration of chloride ions and temperature. The representative value of corrosion rate could be used in corrosion prediction models to calculate the remaining service life as demonstrated by the three cases in a bridge over Guadalquivir River in the south part of Spain, a loading platform in a harbor on the south coast of Spain and a pilot container for radioactive waste storage, respectively [8]. Owing to the extreme complexity and dynamic situation of real application systems, it has been suggested that the corrosion monitoring system may be applied as an integrated part of the whole maintenance, but not the only measure for maintenance.

Broad corrosion criteria have been suggested based on sensor-controlled guard ring device and without sensorcontrolled guard ring device [9]. Ideally, according to the value of corrosion current $\left(i_{\text {corr }}\right)$, the probability for rebar corrosion in concrete or the time-to-corrosion might be predicted. For instance, based on the sensor-controlled guard ring device, $i_{\text {corr }}<0.1 \AA / \mathrm{cm}^{2}$ will lead to passive condition and $i_{\text {corr }}>1 \AA / \mathrm{cm}^{2}$ high corrosion rate, or based on the without sensor-controlled guard ring device, negligible corrosion and corrosion within 2 years will be expected if $i_{\text {corr }}<0.2 \AA / \mathrm{cm}^{2}$ and $i_{\text {corr }}>10 \AA / \mathrm{cm}^{2}$, respectively. However, these limits were found to be strongly affected by temperature and relative humidity. A survey conducted for deck slabs in four-level car park revealed that the corrosion rates measured at the end of the autumn doubled those measured at the end of the winter [10]. Until now, difficulties in validation of onsite measured data still exist and interpretations of the limits defined in the broad corrosion criteria remain to be challenges.

In this work, real-time galvanic corrosion currents, potentials and temperatures were collected by onsite measurements. The corrosion data reported here covered 6 years (approximately 75 months) from the first use of the Xiamen Xiangan Subsea Tunnel to the time of preparation of this paper. The motivation of this investigation was to establish a lifetime corrosion database for the Xiamen Xiangan Subsea Tunnel, through which the health of the subsea tunnel will be dynamically diagnosed and long-term monitored under the normal operating conditions. Ultimately, the prediction of remaining service lifetime based on the real-time database may become possible through future model developments. Since this is an ongoing longterm project, the results included in this paper are rather preliminary. Nevertheless, in the study, an effort has been made to explore the feasibility of onsite corrosion monitoring in the subsea tunnel with embedded commercial sensors and examine the validity of real-time corrosion data.

\section{Experimental}

\subsection{Establishment of Long-Term Field Corrosion Monitoring System}

A series of diversified corrosion sensors, namely the currently under development and commercially available sensors, were pre-embedded into the carefully selected locations and positions in the supporting structures of the Xiamen Xiangan Subsea Tunnel. Figure 1 schematically shows the side view (a) and top view (b) of the subsea tunnel.

As depicted in Fig. 1a, the subsea tunnel connects the Xiamen Island (left side) and Xiangan District (right side) with the undersea length of $4.2 \mathrm{~km}$. The locations labeled as F1, F3 and F4 are selected as the onsite monitoring sections because they present the most dangerous structures in the tunnel. The top view in Fig. 1b illustrates the driving directions within the subsea tunnel. The upper right-to-left arrows indicate the "Enter" direction (arriving Xiamen Island), while the lower left-to-right arrows the "Exit" direction (leaving Xiamen Island). The F1 and F4 sections are located on the entrance site with the sensor boxes named as Enter I and Enter II, respectively. The F3 section is located on the opposite site with the sensor box named as 
(a)

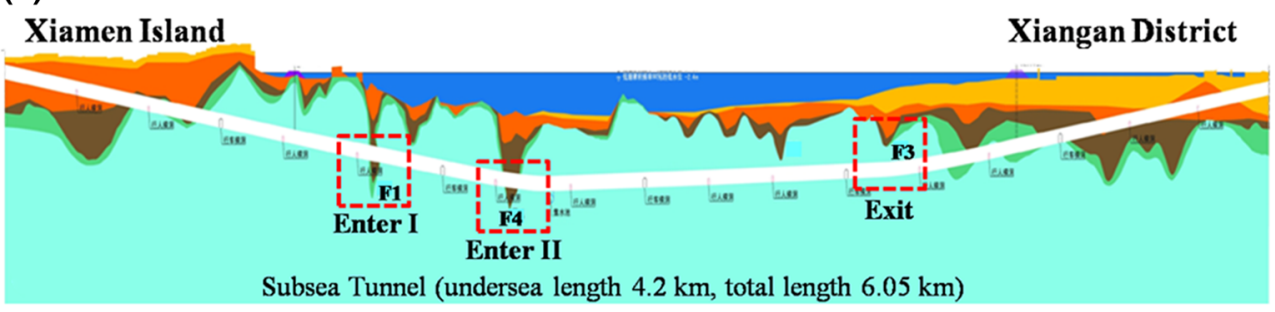

(b)
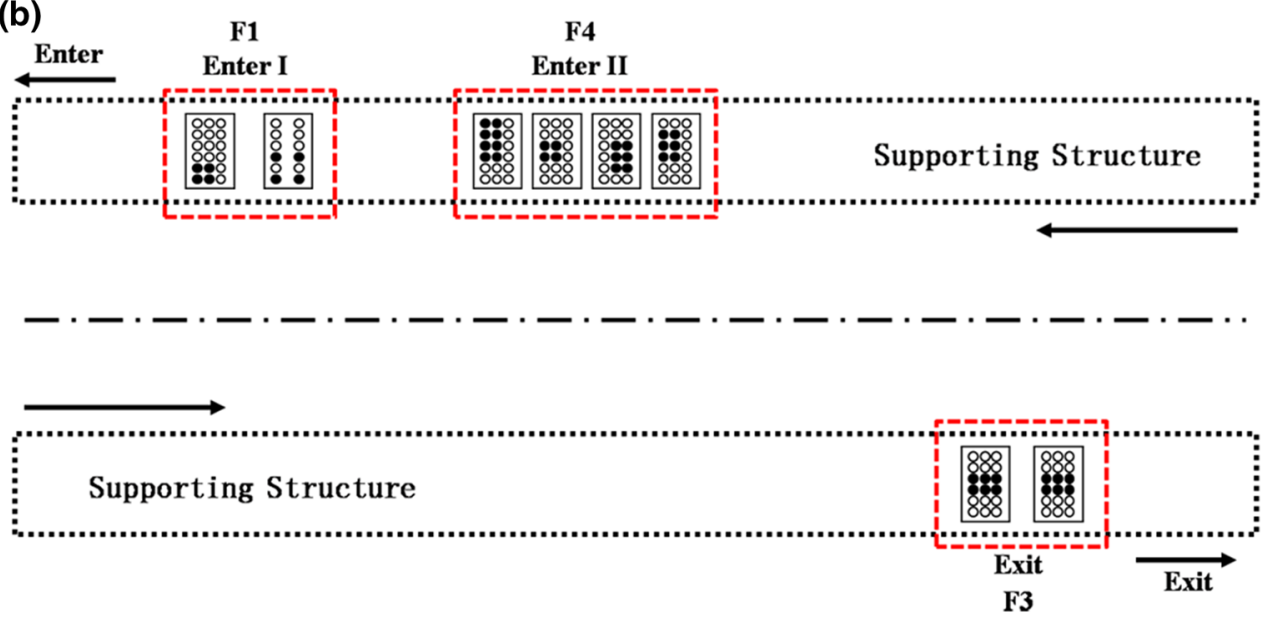

Fig. 1 Schematic representations of three onsite corrosion monitoring locations selected in the supporting structures of Xiamen Xiangan Subsea Tunnel. a Side view; b top view

Exit. The solid circles in sensor boxes refer to the CorroWatch corrosion sensors, while the open circles to the homemade corrosion sensors which are under testing. In addition, at the same monitoring section, the sensors were embedded in the supporting structures at different positions with different orientations, as described in Fig. 2. Three positions including vault (1), left (2) and right (3) with two orientations, either faced (A-C-E) or opposite (B-D-F) to the tunnel, were employed for the sensor embedment. Therefore, the long-term field corrosion monitoring system

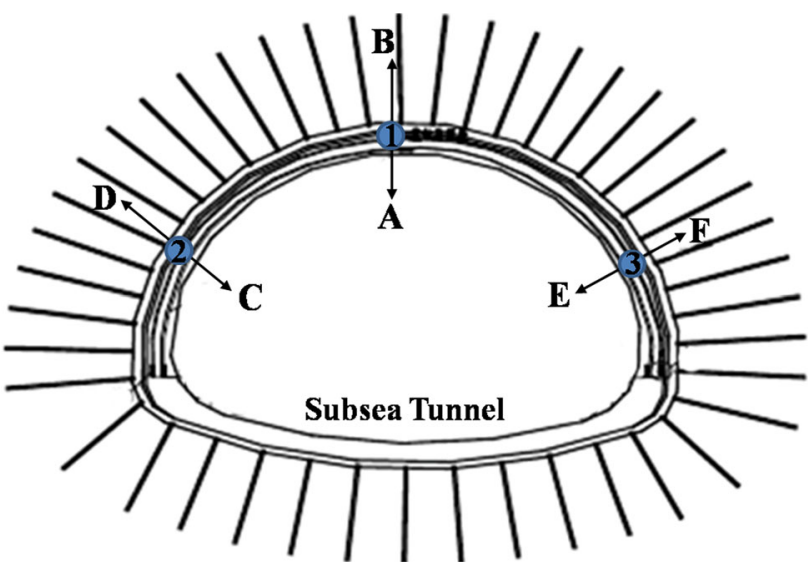

Fig. 2 Positions and directions of the sensor embedment in the monitoring section. Sensor positions: 1 vault; 2 left; 3 right; sensor directions: A-C-E: faced to tunnel; B-D-F: opposite to tunnel was successfully established in the supporting structures of Xiamen Xiangan Subsea Tunnel. The onsite measurements were performed annually at the three locations and fourteen positions as listed below.

(1) Enter I-A, Enter I-B

(2) Enter II-A, Enter II-B, Enter II-C, Enter II-D, Enter II-E, Enter II-F

(3) Exit-A, Exit-B, Exit-C, Exit-D, Exit-E, Exit-F

The CorroWatch multiprobe sensors with a built-in temperature sensor [11] and the ERE-20 reference electrodes [12], purchased from the Force Technology (Denmark), were installed in the field by experienced engineers prior to pouring of the concrete during the tunnel constructions, as seen in Fig. 3a, b. The CorroWatch sensor consists of four anodes and one ring cathode (Fig. 3c). The four anodes are made of black steel and oriented toward different directions with the concrete covers varying from 48 to $33 \mathrm{~mm}$. Rebar corrosion will firstly start with Anode 1 when carbonate or chloride reaches the critical interface of concrete cover. In principle, the currents passing through the macrocells made of every anode and the cathode can be simultaneously measured, and therefore, the values of Icorr(1), Icorr(2), Icorr(3) and Icorr(4) are obtained. At the same time, the potentials between every anode and the reference electrode (Fig. 3b), i.e., the values of Ecorr(1), Ecorr(2), Ecorr(3) and Ecorr(4), are also measured. The 

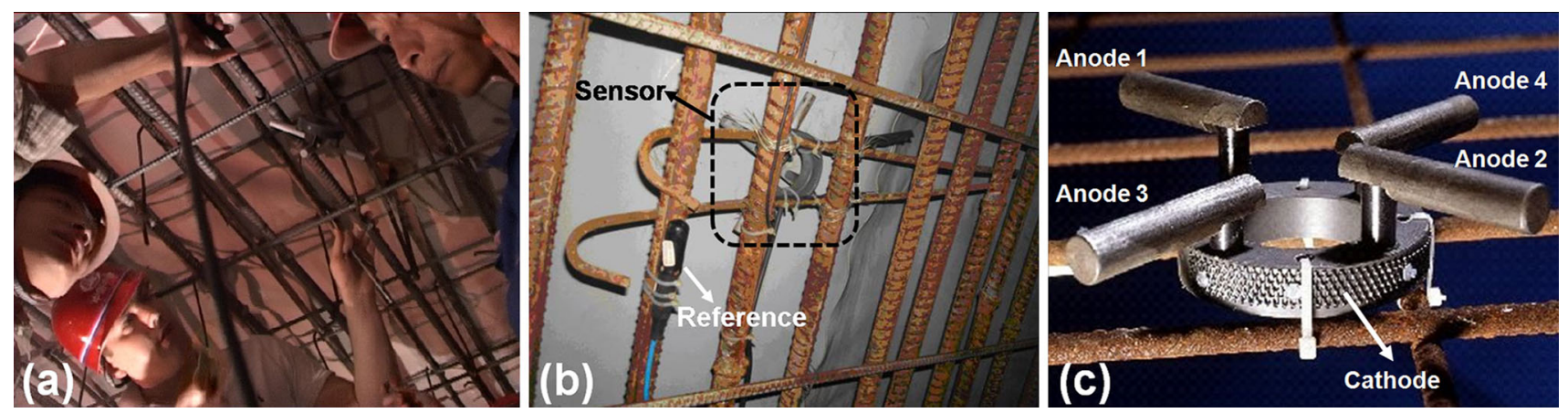

Fig. 3 Photographs showing the field installations of CorroWatch sensor and ERE-20 reference electrode $\mathbf{a}, \mathbf{b}$, the CorroWatch sensor consisting of four anodes and one ring cathode c

commercial ERE-20 reference electrode is an embeddable manganese dioxide $\left(\mathrm{MnO}_{2}\right)$ electrode, and the average potentials were $167-172 \mathrm{~V}$ at $23-40{ }^{\circ} \mathrm{C}$ obtained by using $10 \mathrm{MnO}_{2}$ electrodes measured against a saturated calomel electrode in a thermostatted bath of saturated $\mathrm{Ca}(\mathrm{OH})_{2}[13]$. Theoretically speaking, the soonest possible corrosion should be indicated by the values measured with the sensor embedded most closely to the concrete surface, i.e., the values of Icorr(1) and Ecorr(1). Furthermore, the instantaneous temperature at the vicinity of the sensors and concrete (Tcorr) is automatically recorded during each measurement. With the combination of real-time Icorr(1-4), Ecorr(1-4) and Tcorr data, the reinforcement corrosion in concrete structures can be in situ investigated and onsite monitored. It should be pointed out that the corrosion currents measured by the commercial CorroWatch multiprobe sensors in this investigation are the galvanic currents flowing between the black steel and the cathode. They are not corrosion currents. Thus, the Icorr is used to differentiate the conventional corrosion current $\left(i_{\text {corr }}\right)$.

\subsection{Collection of Real-Time Corrosion Data}

The real-time corrosion data [Icorr(1-4), Ecorr(1-4) and Tcorr] were measured with the embedded corrosion sensors at the three locations (Enter I, Enter II, Exit in Fig. 1) and different positions/directions (Vault-Left-Right/A-B-CD-E-F in Fig. 2) by using a portable data acquisition instrument (Force Technology, Denmark) and a laptop computer. The onsite measurements have been made routinely under the normal tunnel operation except the starting data which were measured before the tunnel operation. For safety, the real-time data are usually collected during the time period of night to midnight with lighter traffic load in the subsea tunnel. As this is a long-term research project, the uppermost priority of this work was to validate the feasibility of the practical onsite corrosion monitoring system and to establish suitable criteria for the long-term corrosion investigation of the Xiamen Xiangan Subsea Tunnel. For the sake of simplicity, only the selected results based on the realtime data measured with the CorroWatch sensors and ERE20 reference electrodes are reported and briefly discussed. The data analyses in stability and performance of the homemade corrosion sensors are beyond the scope of this paper.

\section{Preliminary Results}

The preliminary results presented here are the real-time data available upon the time of the paper preparation (June 2016). Once the onsite corrosion monitoring system was established, the first and most important task of this work was to understand the data responses which signify the real situation of the monitoring position. The real-time Icorr and Ecorr data for the location of Enter I-A were measured right after the completion of the sensor embedment on September 26, 2008, and the screenshots for the first 12 points are provided in Fig. 4a, b. As evident in Fig. 4a, all the Icorr(1-4) values were less than $1 \AA / \mathrm{cm}^{2}$. However, the Icorr(1) values appeared slightly negative $(-0.02$ to $-0.04 \AA / \mathrm{cm}^{2}$ ), which might be caused by artifacts. The Icorr(2) varied in the range of $0.5-0.7 \AA / \mathrm{cm}^{2}$ and displayed the largest values, while the Icorr(4) reduced most significantly from 0.6 to $0.1 \AA / \mathrm{cm}^{2}$. On the other hand, the Ecorr data in Fig. 4b reveals that the Ecorr(1) responded most significantly and approached the most positive value of $-100 \mathrm{mV}$. The Ecorr(2) attained the most negative value of $-370 \mathrm{mV}$. The Ecorr(4) was the second positive one among the four. However, compared with the Icorr and Ecorr data measured most recently on June 5, 2016, at the same location, the magnitudes of both Icorr and Ecorr were remarkably changed as evident in Fig. 4c, d. The Icorr(1) stabilized at zero and remained the smallest one, while the Icorr(4) took the maximum value of $25-30 \AA / \mathrm{cm}^{2}$ (instead of Icorr(2) in Fig. 4a). The Ecorr in Fig. 4d responded in 

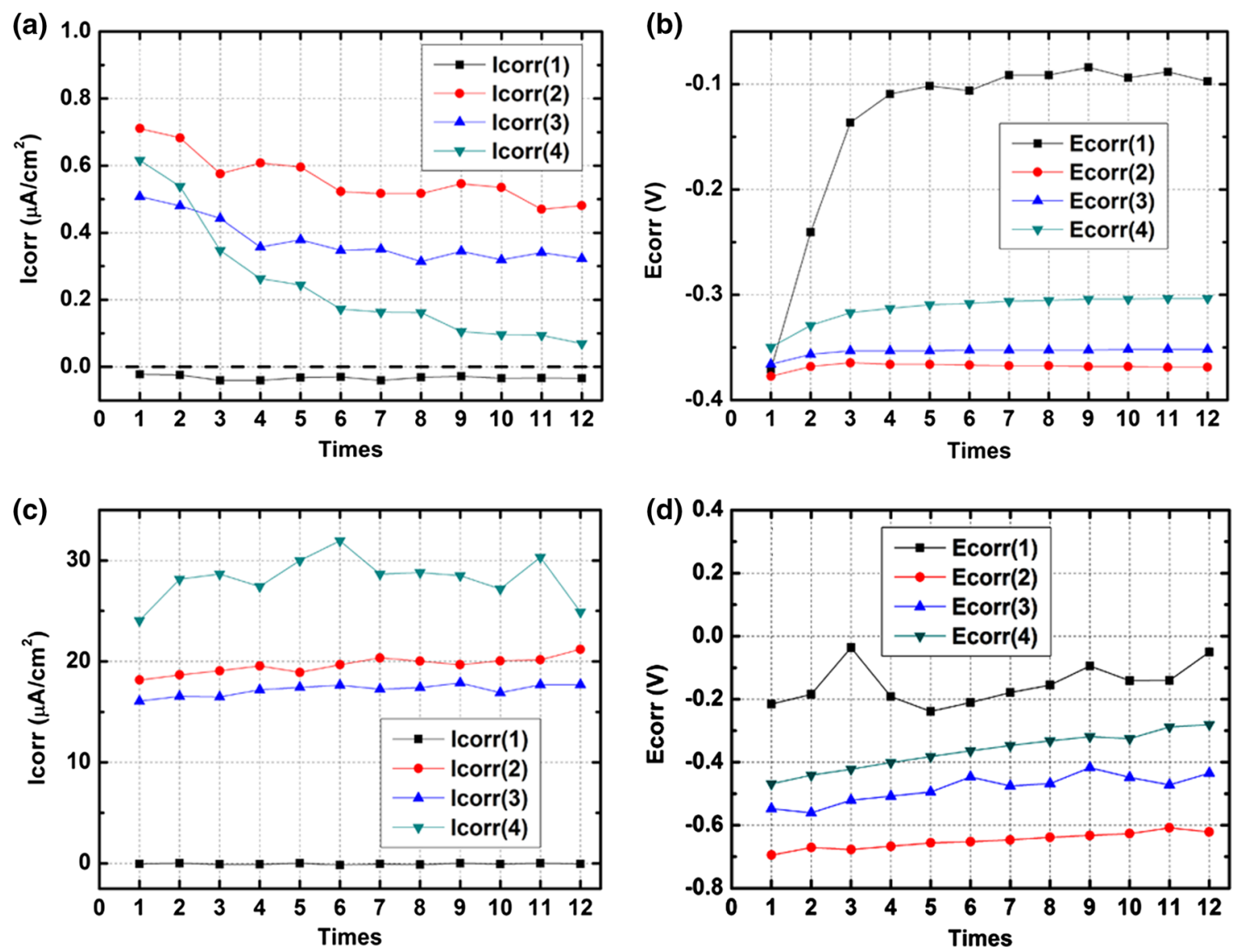

Fig. 4 Typical corrosion currents and potentials obtained from the onsite measurements by means of CorroWatch sensors at the same location of Enter I-A. a, b Screenshots on September 26, 2008; c, d plots on June 5, 2016

the similar sequential order to those in Fig. $4 \mathrm{~b}$, that is, Ecorr(1) responded most positively, while Ecorr(4) least positively. These observations suggested that the Icorr/ Ecorr responses near the concrete cover (Icorr(1)/Ecorr(1)) and rebar surface (Icorr(4)/Ecorr(4)) were more susceptible to time changes. The CorroWatch sensors combined with the ERE-20 reference electrode are sensitive and feasible to onsite-monitor the dynamical states of the selected location in the supporting structures of the subsea tunnel.

Figure 5 compares the Icorr and Ecorr data measured from two locations, Enter II-A (a, b) and Exit-C (c, d), at the same day. Apparently, in Fig. 5a, c the Icorr(2) values were much higher than those of $\operatorname{Icorr}(1,3,4)$ which were small and less altered (the insets in Fig. 5a, c). The firstpoint Icorr(2) values were $2 \AA / \mathrm{cm}^{2}$ for the location of Enter II-A (Fig. 5a) and $12.5 \AA / \mathrm{cm}^{2}$ for Exit-C (Fig. 5c). However, the Icorr(2) tended to be stabilized at the end of the measurements. The 20th-point $\operatorname{Icorr}(2)$ at the two locations reached 2.5 or $9.8 \AA / \mathrm{cm}^{2}$, all exceed the limits defined in the broad corrosion criteria [9]. As mentioned earlier, the Icorr values measured by the CorroWatch sensors represent the galvanic currents flowing through a black steel anode and a nobler cathode, the conventional criteria associated with corrosion current $\left(i_{\text {corr }}\right)$ cannot be directly applied in this investigation. On the other hand, the Ecorr responded more complicatedly. At the location of Enter II-A, Ecorr(1) showed the most positive value and stabilized near 0.6 V (Fig. 5b), while at Exit-C, Ecorr(1) the least positive one around $-0.4 \mathrm{~V}$ and gradually approached to $0 \mathrm{~V}$ (Fig. 5d). The Ecorr $(2,3,4)$ had a tendency to increase slightly at the two locations, and more obvious fluctuation in Ecorr $(2,3,4)$ occurred at Enter II-A (Fig. 5b). A missing Ecorr(1) data was also observed as indicated by a dashed rectangle in Fig. 5d, which occurred occasionally in this investigation as the onsite measurements were carried out under the dynamic situation. The results in Figs. 4 and 5 suggest that the baselines for Icorr and Ecorr vary significantly from time to time and location to location. The representative corrosion response cannot rely only on a single set of data readings when undertaking the onsite monitoring work in field.

To further examine the dynamic situation of the Xiamen Xiangan Subsea Tunnel during the normal operation, the selected real-time Icorr and Ecorr data collected continuously for 6 years at the three monitoring locations with the sensors being embedded at the same position $(1-$ vault in 

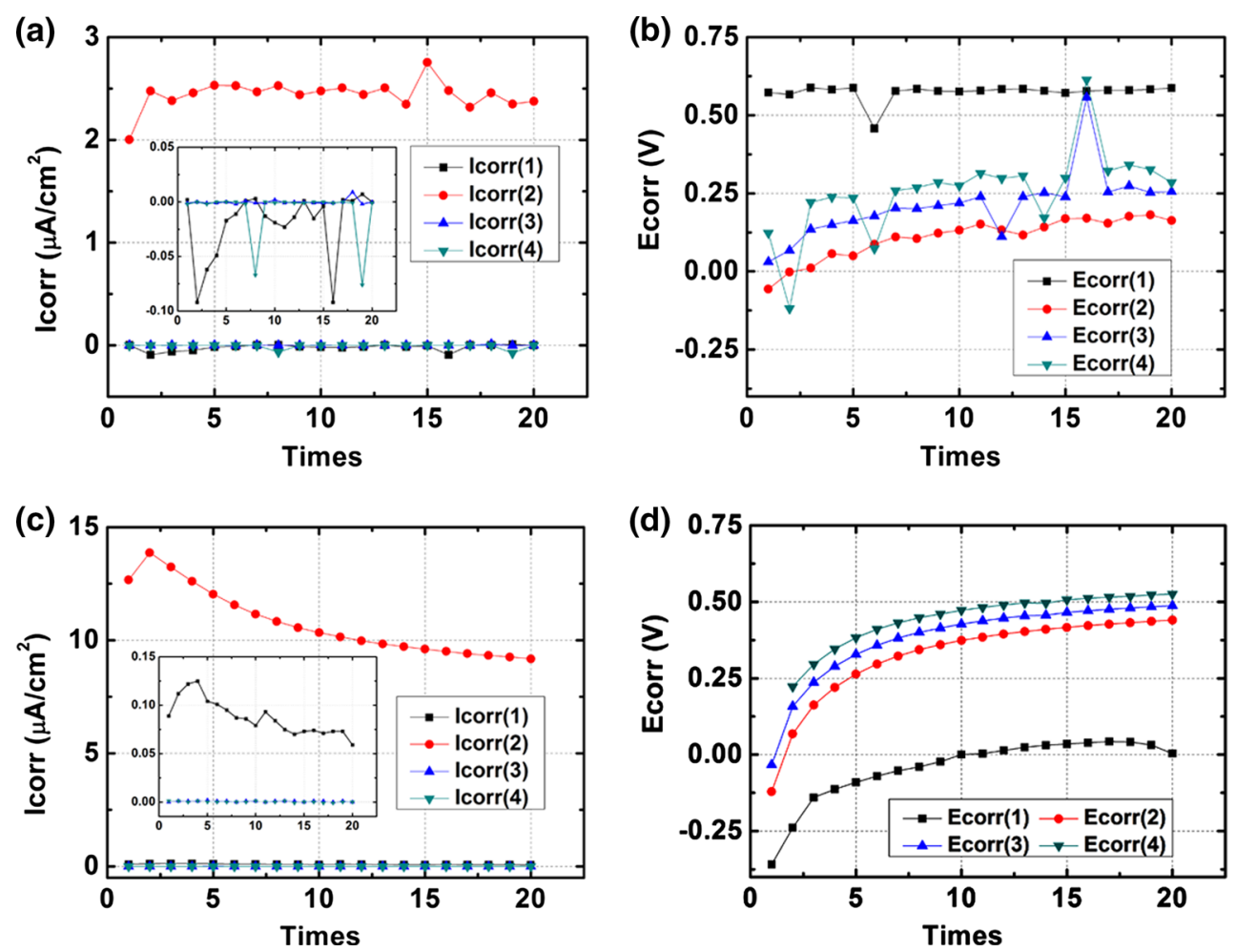

Fig. 5 Typical real-time corrosion currents $\mathbf{a}, \mathbf{c}$ and potentials $\mathbf{b}, \mathbf{d}$ measured for the first 20 points on February 28,2016 at different locations. a, b Enter II-A; c, d Exit-C. The insets in a, c are the Icorr(1-3) responses at an enlarged scale
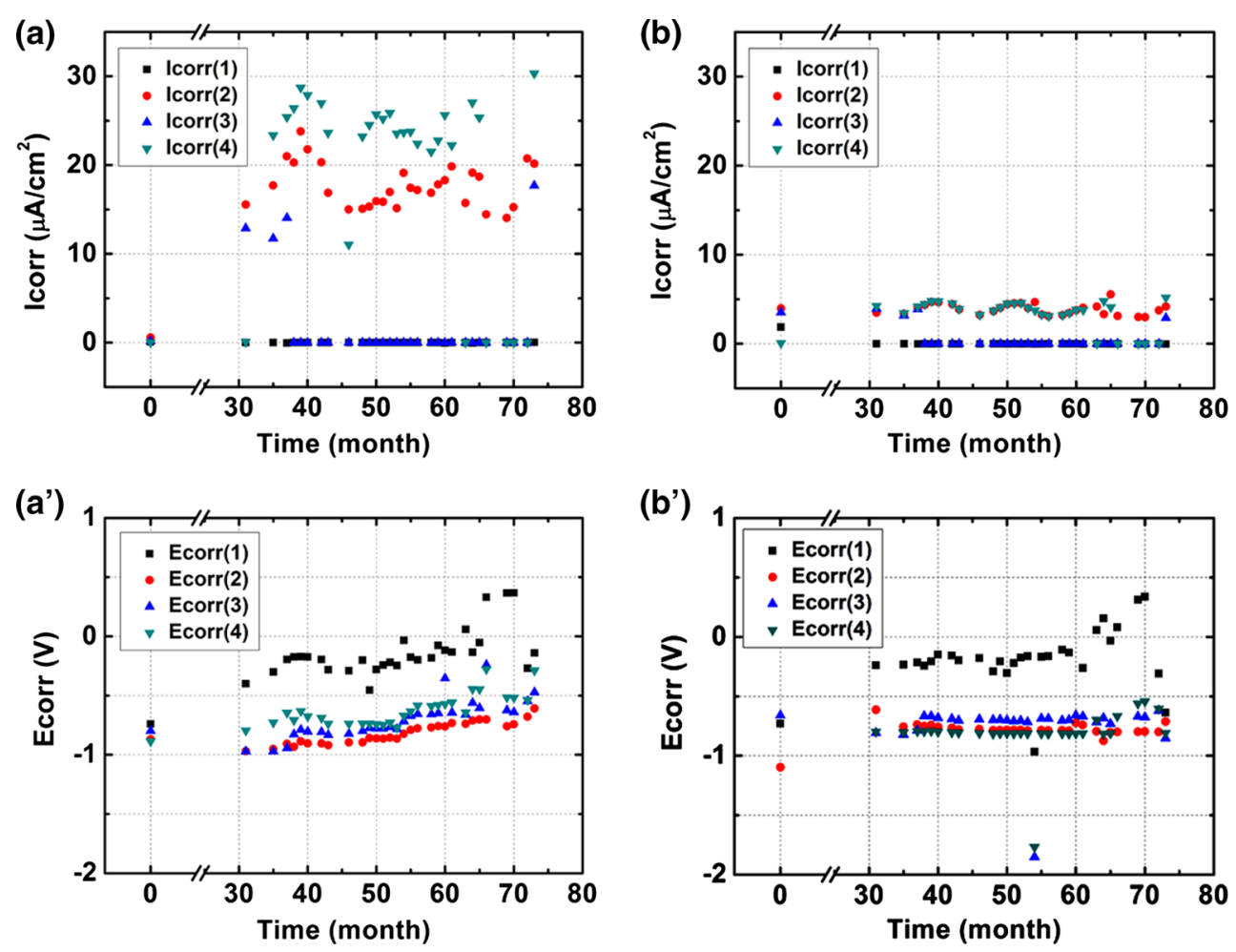

Fig. 6 Real-time corrosion data for the locations of Enter I-A a, $\mathbf{a}^{\prime}$ Enter I-B b, $\mathbf{b}^{\prime}$ 

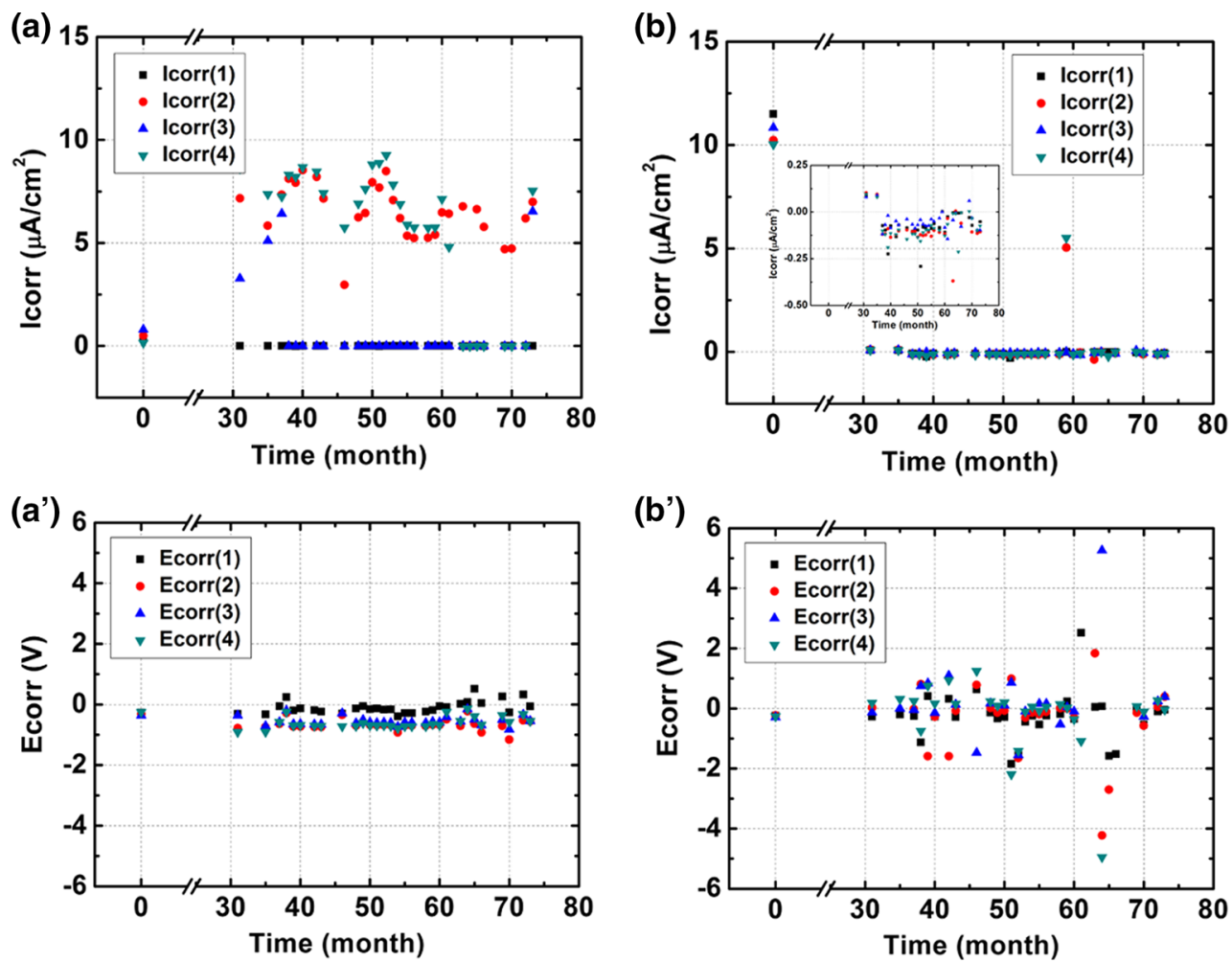

Fig. 7 Real-time corrosion data for the locations of Enter II-A a, $\mathbf{a}^{\prime}$ Enter II-B b, $\mathbf{b}^{\prime}$
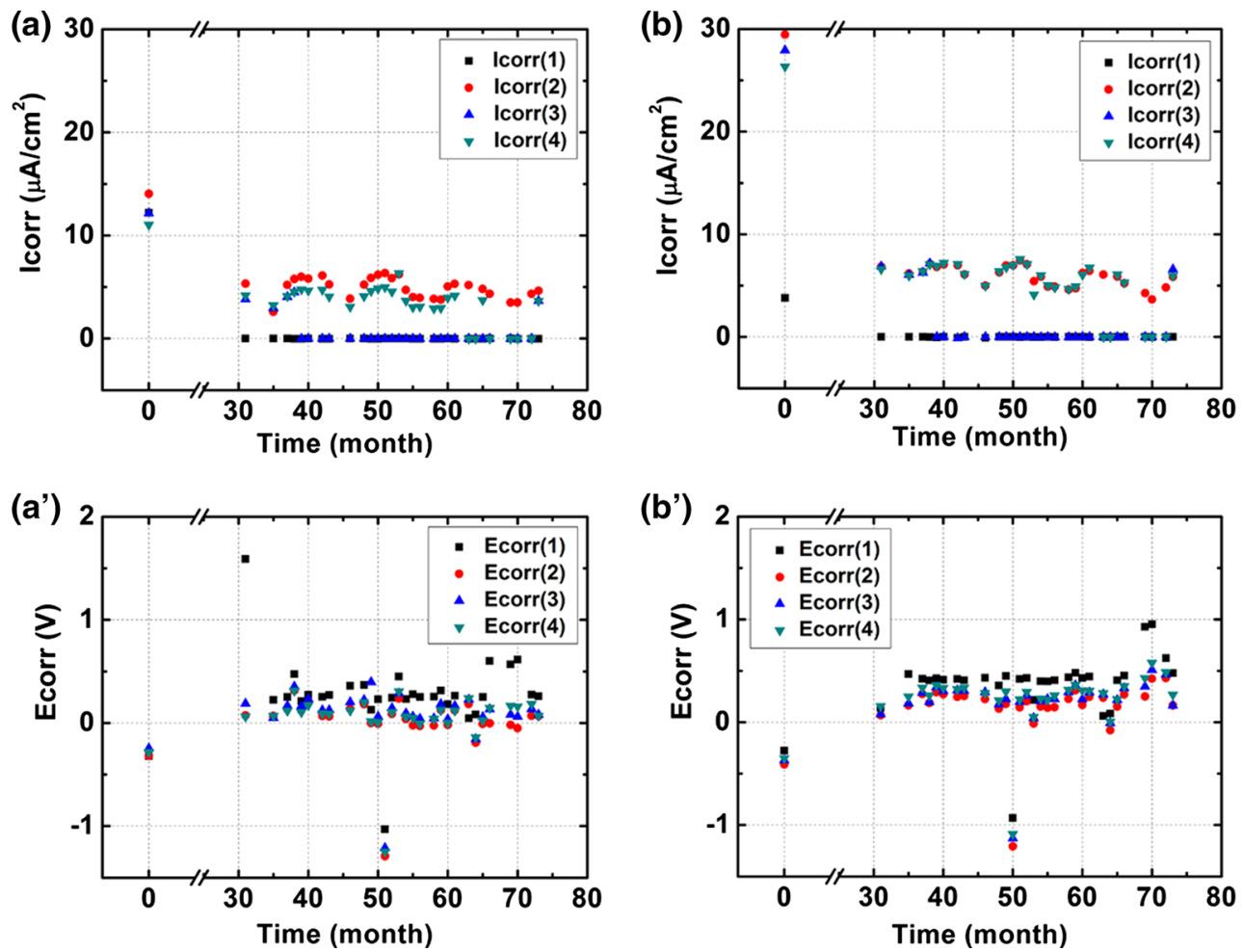

Fig. 8 Real-time corrosion data for the locations of Exit-A a, $\mathbf{a}^{\prime}$ Exit-B b, $\mathbf{b}^{\prime}$

Fig. 2) and directions (A-faced and B-opposite to tunnel in Fig. 2) are presented in Figs. 6, 7, and 8. The 2nd-point data are plotted in the figures. The Icorr and Ecorr data measured before the tunnel operation were taken as the starting values, i.e., the data at time of 0 in the plots. It is interesting to note that in most cases the apparent cyclic 
changes, in particular, Icorr, with the increases in monitoring time were observed for all the three locations. The starting values of Icorr and Ecorr varied from location to location, and most of them were beyond the limits defined by the broad corrosion criteria [10]. The reinforcement corrosion in concrete is generally considered as a slow process. It is expected that no severe corrosion would take place at this stage. The large values of Icorr and Ecorr observed from those locations might imply that the CorroWatch sensors are very sensitive to the local changes of interface species and concrete environments such as moisture and temperature. The apparent cyclic changes and large fluctuations of Icorr and Ecorr seen in Figs. 6, 7 and 8 might be more closely related to the alterations in tunnel environments such as temperature, relative humidity and traffic load. It appeared that the corrosion sensors might be too sensitive in practical applications as compared in laboratory experiments. However, the long-term dynamic changes in the real-time Icorr and Ecorr data may present a general trend or pattern for future correlation of corrosion behavior of the subsea tunnel. This ongoing research work involving long-term onsite corrosion monitoring with the embedded corrosion sensors will provide scientific basis for development of suitable corrosion criterion and new diagnosing methodology applicable in engineering structures.

\section{Discussion}

As mentioned earlier, the four anodes in the CorroWatch sensor have small concrete covers $(48-33 \mathrm{~mm})$, and the soonest corrosion might be indicated by the values of Icorr(1) and Ecorr(1). Figure 9 plots all the real-time Icorr(1) and Ecorr(1) data measured from the three locations (Enter I, Enter II and Exit in Fig. 1) and various sensor positions (A-F in Fig. 2) against the monitoring time. The data at time of 0 represent the starting values obtained before the tunnel operation. Clearly, the starting values of Icorr(1) ranged broadly from 0 to $35 \AA / \mathrm{cm}^{2}$ (Fig. 9a), while those of Ecorr(1) fell between 0 and $-1 \mathrm{~V}$ (Fig. 9b). The extremely large initial Icorr values obtained might be artifacts as the data were measured during the tunnel construction. Almost all the Icorr(1) data measured after the tunnel operation were smaller than $0.2 \AA / \mathrm{cm}^{2}$ and distributed in the region of $0 \sim 0.05 \AA / \mathrm{cm}^{2}$, as evident in Fig. $9 a^{\prime}$. Therefore, the $\operatorname{Icorr}(1)$ values measured with CorroWatch multiprobe sensors after the tunnel operation are considered to be smaller than $0.1 \AA / \mathrm{cm}^{2}$ based on Fig. $9 \mathrm{a}^{\prime}$, suggesting that the supporting structures of the Xiamen Xiangan Subsea Tunnel are safe. In the case of Ecorr(1), this parameter assists to monitor the concrete environment. The variation in Ecorr(1) might indicate the local differences in concrete environment caused by the presence of more or less chloride, oxygen and other corrosive conditions, which will significantly affect the concrete durability. The initial Ecorr(1) data in Fig. 9b scattered very broadly but varied mainly in the range of -1

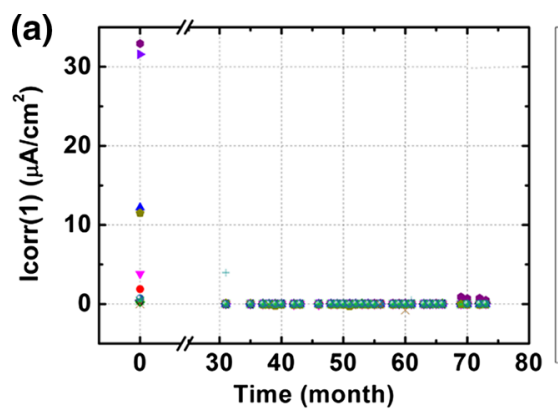

(b)

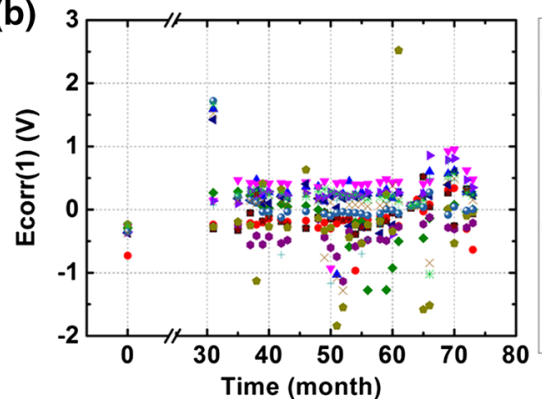

(a')

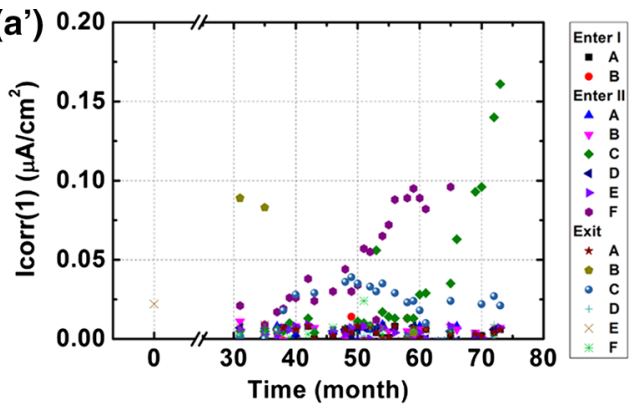

(b')

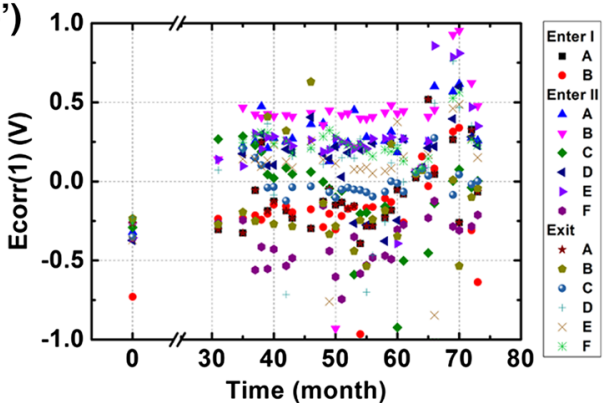

Fig. 9 Real-time $\operatorname{Icorr}(1) \mathbf{a}, \mathbf{a}^{\prime} \operatorname{Ecorr}(1) \mathbf{b}, \mathbf{b}^{\prime}$ as a function of monitoring time 


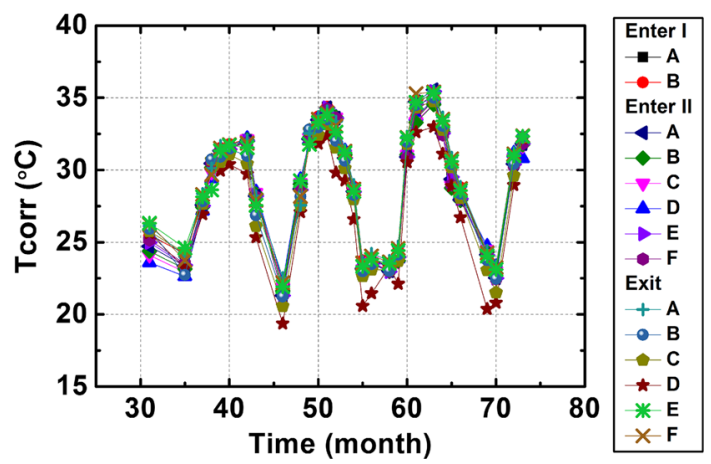

Fig. 10 Variation of Tcorr with the monitoring time at different locations and positions

to $1 \mathrm{~V}$, which can be more obviously visualized in Fig. $9 \mathrm{~b}^{\prime}$. Compared with the large starting values of Icorr(1) (time $=0$ ) in Fig. 9a, the most starting values of Ecorr(1) $\left(\right.$ time $=0$ ) in Fig. $9 \mathrm{~b}^{\prime}$ were negative and less than $-0.5 \mathrm{~V}$ except the one at the location of Enter I, B. Apparently, the Ecorr(1) data measured during the subsea tunnel operation fluctuated more severely between -0.5 and $0.5 \mathrm{~V}$. In this case, the wide variation in Ecorr(1) might be caused by the temporal fluctuation in the local vicinity due to the instantaneous changes of moisture and temperature at rebar/concrete interface or in concrete. Since the real situation in the field is very complex, the preliminary results presented here are the real-time data collected under the tunnel operation and represent the dynamic states of the selected corrosion monitoring positions, and special attention and careful analysis are needed for the reasonable interpretation of the real-time corrosion data. In particular, the Icorr(1-4) data measured here are based on the macrocell principle and differ from those conventional corrosion currents reported from literature. It is, therefore, more important to establish the baseline as a healthy state for the subsea tunnel. The suitable and applicable corrosion criterion requires more in-depth investigation in future work.

Figure 10 gives the Tcorr-time plot for the three monitoring locations and different sensor-embedded positions. The typical cyclic responses of temperature with monitoring time directly reflected the seasonal changes since the onsite measurements have been done annually. The Tcorr values slightly differed from one location to another location as the completion of the onsite measurements required a few hours. Interestingly, the cyclic changes were observed in Figs. 6, 7 and 8, especially for Icorr. Whether these cyclic patterns are associated with the temperature alternation owing to seasonal changes remained unclear at this stage. Future work will be continued to explore and understand this phenomenon.

\section{Conclusion}

With the establishment of onsite corrosion monitoring system in the supporting structures of the Xiamen Xiangan Subsea Tunnel in China, the real-time corrosion data including galvanic corrosion currents (Icorr), potentials (Ecorr) and temperatures (Tcorr) were collected annually with the pre-embedded CorroWatch multiprobe sensors and ERE-20 reference electrodes before and during the tunnel operation. This ongoing work has demonstrated that the onsite corrosion monitoring in the marine structure is possible and the long-term dynamical corrosion behavior of subsea tunnel can be studied. Based on the preliminary corrosion data collected for more than 70 months, it was found that the starting values of Icorr and Ecorr, measured before the tunnel operation, varied appreciably from location to location. The Icorr and Ecorr obtained at the same location and with the same sensor also changed from time to time. The conventional corrosion criteria were not suitable for the present applications. However, the measured long-term Icorr(1) and Ecorr(1) values might be meaningful to identify the dynamic situation of the subsea tunnel. Most real-time Icorr and Ecorr data have cyclic responses, similar to the cyclic variation in Tcorr corresponding to seasonal changes. Future work will be continued to provide more comprehensive understanding and scientific basis for onsite corrosion monitoring applications in engineering structures exposed to marine environments.

Acknowledgements Authors wish to thank the financial support and onsite assistance from the Xiamen Road and Bridge Construction Group Co., Ltd., China. The graduate students of Xiamen University in China who have made contributions to the real-time data collections are greatly appreciated.

\section{References}

[1] S. Ahmad, Cement Concr. Compos. 25, 459 (2003)

[2] S. Ahmad, Int. J. Electrochem. Sci. 2, 1 (2007)

[3] M. Raupach, P. Schiessl, Constr. Building Mater. 11, 207 (1997)

[4] M. Raupach, P. Schiessl, NDT\&E Int. 34, 435 (2001)

[5] G. Gudmundsson, On site monitoring of high performance concrete during freeze/thaw cycles and relationship to standardized testing. in Proceedings 15th International Baustofftagung, September 2003, Germany. doi:10.13140/ RG.2.1.4017.1608

[6] http://corrosioninstrument.com

[7] S.G. Dong, C.J. Lin, R.G. Hu, L.Q. Lin, R.G. Du, Electrochim. Acta 56, 1881 (2011)

[8] M. Raupach, P. Schiessl, Cement Concr. Compos. 31, 545 (2009)

[9] C. Andrade, M.C. Alonso, J.A. Gonzalez, An initial effort to use corrosion rate measurements for estimating rebar durability corrosion rates of steel in concrete, in ASTM STP 1065, vol. 29, ed. by N.S. Berke, et al. (ASTM, West Conshohocken, 1990)

[10] M.G. Grantham, J. Broomfield, Constr. Building Mater. 11, 215 (1997) 
[11] http://www.pcte.com.au/corrowatch-embeddable-corrosion-frontprobes

[12] http://www.pcte.com.au/ere20-embeddable-reference-electrodesfor-cp-and-corrosion-monitoring
[13] H. Arup, O. Klinghoffer, J. Mietz, Corrosion/97, vol. 243 (NACE, Houston, 1997) 